\begin{abstract}
\begin{tabular}{llllllll} 
A & B & S & T & R & A & C & T \\
\hline
\end{tabular}
This study describes factors influencing infant feeding choices of 434 mothers with 9month-old infants in Vancouver. Consistent with Social Cognitive Theory, both internal personal and socio-environmental factors influence infant feeding choices. Mothers attributed the choice to breastfeed primarily to personal choice, whereas the choice to formula feed was attributed to socio-environmental factors. Among mothers who breastfed $<3$ months, the choice to wean was primarily attributed to concern for baby's nutrition; compared to returning to work, concern about milk supply and concern for baby's nutrition among those who breastfed $\geq 3$ to $<6$ months; and returning to work and personal choice among those who breastfed $\geq 6$ months. Among Caucasian mothers, the choice to wean was primarily attributed to returning to work, compared to concern for baby's nutrition among non-Caucasian mothers. Initiatives to facilitate further advances in breastfeeding promotion could address three areas: 1) prenatal intentions, 2) early postpartum concerns, and 3) later issues surrounding returning to work and infant nutrition.
\end{abstract}

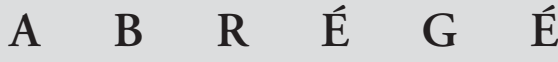

Cette étude décrit les facteurs influant sur les choix en matière d'alimentation faits par 434 mères de nourissons âgés de 9 mois. Conformément à la théorie cognitive sociale, des facteurs personnels et socio-environnementaux influent sur les choix en matière d'alimentation des nourissons. Les mères attribuent principalement le fait d'allaiter à un choix personnel tandis que l'alimentation au moyen de préparations est attribué à des facteurs socioenvironnementaux. La principale raison motivant le sevrage était le souci de l'alimentation du bébé, comparativement au retour au travail, chez les mères ayant allaité durant moins de 3 mois; le souci par rapport à la qualité du lait et l'alimentation du bébé chez celles ayant allaité pendant une période de 3 à 6 mois; et le retour au travail et un choix personnel parmi celles qui avaient allaité pendant 6 mois ou plus. Parmi les mères de race blanche, le retour au travail était la principale motivation comparativement au souci de l'alimentation du bébé chez les mères des autres races. Des initiatives visant à faciliter la promotion de l'allaitement au sein pourraient répondre aux trois questions suivantes : les intentions des mères avant l'accouchement, les problèmes survenant lors des premiers jours du post-partum et finalement les questions relatives au retour en milieu de travail et à l'alimentation des enfants.

\title{
Factors Influencing Infant Feeding Practices of Mothers in Vancouver
}

\author{
Patricia L. Williams, $B S c, P D t,{ }^{1}$ Sheila M. Innis, $P h D,{ }^{1}$ \\ A.M.P. Vogel, $M D{ }^{2}$ Loraina J. Stephen, $B S c^{3}$
}

Despite the increases in breastfeeding rates in Canada throughout the 1970s and early $1980 \mathrm{~s},{ }^{1-4}$ rates have plateaued in more recent years..$^{5-8}$ Compared to national rates of $73 \%$, initiation rates are strikingly lower among women who are younger, from non-Caucasian ancestries, ${ }^{2,5}$ lower socioeconomic backgrounds, ${ }^{2,5-7}$ or from Eastern Canada. ${ }^{8}$ In addition, early termination of breastfeeding continues to be reported. ${ }^{2,5-8}$ Low initiation rates and short duration, in general, persist ${ }^{2,5-8}$ despite recommendations to promote, protect and support breastfeeding for at least 9 to 12 months. ${ }^{9-13}$

Numerous studies have examined factors that influence a mother's infant feeding practices. Maternal age, ${ }^{14-17}$ education, ${ }^{5,14-}$ $16,18,19$ income, ${ }^{4,5,17,18}$ marital status, ${ }^{5,15}$ ethnicity ${ }^{5,14,16}$ and the way the mother herself was $\mathrm{fed}^{20}$ are correlated with breastfeeding initiation and duration. Although demographic factors are strong predictors, complex psychosocial variables such as knowledge, attitudes and beliefs are more important and modifiable determinants of infant feeding practices. ${ }^{21,22}$ Further advances in improving breastfeeding rates might come from a better understanding of the influencing factors surrounding breastfeeding and early weaning. This study describes factors which mothers reported to influ-

1. Department of Paediatrics, Faculty of Medicine, University of British Columbia, Vancouver, BC

2. City of Vancouver Health Department, Vancouver, BC

3. School of Family and Nutritional Sciences, University of British Columbia, Vancouver, BC

Correspondence and reprint requests: Professor Sheila M. Innis, Department of Paediatrics, University of British Columbia, B.C. Research Institute for Child and Family Health, 950 West 28th Avenue, Vancouver, BC, V5Z 4H4, Tel: 604875-2431, Fax: 604-875-2226

Supported by a grant from the B.C. Medical Services Foundation with assistance from the Vancouver Health Department. ence their choice to: 1) breastfeed or formula-feed, and 2) wean to an infant formula or cow's milk.

\section{METHODS}

Descriptive information was collected as part of a cross-sectional study on the prevalence of iron deficiency anaemia among 9month-old infants. ${ }^{23}$ Study participants were identified from birth lists provided by the Vancouver Health Department. Initial contact was made by letter to parents of all term (37-42 weeks gestation) infants, birthweight 2500-4500g, born between January 1 st and March 2nd, or June 4th and August 7th, 1993, resident in the City of Vancouver $(\mathrm{n}=1,813)$. Subsequent telephone contact was used to describe the study protocol and arrange appointments for those parents interested in participating. All infants were $39 \pm 1$ week of age when they attended the research clinic, during which the study information was collected. Written informed consent was obtained from all parents. The study protocol and procedures were approved by the University of British Columbia Screening Committee for Research Involving Human Subjects.

Two standardized, self-completion questionnaires were used: a confidential demographic questionnaire consisting of 6 items, and a questionnaire consisting of 17 items on infant feeding practices from birth to nine months of age. The infant feeding questionnaire contained items on duration of breast- or formula-feeding, age of introduction of formula and cow's milk and factors influencing infant feeding choices. A list of potential factors influencing feeding choices was compiled from literature review, expert consultation, and pilot testing with mothers. Mothers were 
asked to check the factors they felt influenced their infant feeding decisions. An open box allowed additional factors to be added. Questionnaires were available in English and Chinese. Completed infant feeding questionnaires were reviewed with the mother by a research nutritionist.

To identify factors influencing infant feeding practices, mothers were grouped by duration of breastfeeding as $<3$ months, $\geq 3$ to $<6$ months, and $\geq 6$ months, and by ethnic background as Caucasian and nonCaucasian. For the purposes of this study, an infant was considered exclusively breastfed as long as formula-feeding did not exceed 250 $\mathrm{mL}$ per week. Solid foods and juice were not considered in this study classification. Frequencies of responses were compared for categorical variables, i.e., factors influencing infant feeding choices among groups, by the chi square statistics and Fisher exact tests using the Statistical Packages for the Social Sciences, release 7.0 (SPSS, Inc., Chicago, IL). The risk of an inflated type I error due to the number of comparisons being made needs to be considered. Therefore, for the purpose of discussion in this study, a $\mathrm{p}$ value of 0.001 was considered significant.

\section{RESULTS}

\section{Study population}

This study involved 434 mothers, representing $24 \%$ of the 1,813 to whom letters describing the study were sent. One mother who breastfed and six who used formula did not answer the questions concerning the factors influencing their infant feeding practices. Over half the mothers were 30 years of age or older, and $90 \%$ were married. Thirty-four percent had family incomes of \$50,000 or more and 73\% had either a college or university education. Data on the iron status ${ }^{23}$ and the infant feeding practices ${ }^{5}$ in this group of infants have been previously published.

Factors influencing mothers' choice to breastfeed or formula-feed

Of the 434 mothers in the study, 360 (83\%) breastfed, 332 breastfed exclusively (77\%), 7\% both breastfed and formula-fed and $74(17 \%)$ gave formula with no breastfeeding from birth. The factor cited most frequently for influencing the choice

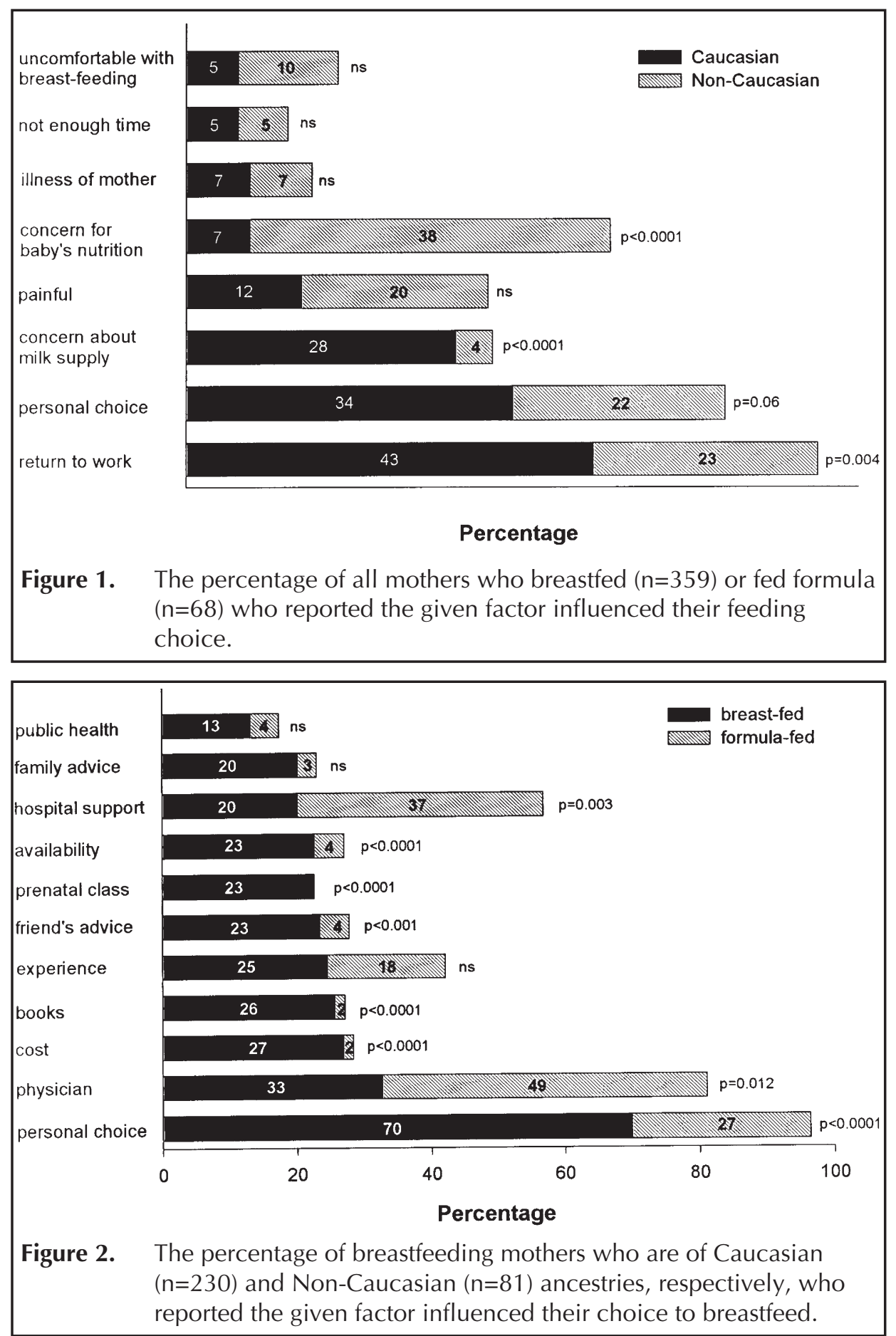

to breastfeed was personal choice (cited by $70 \%)$, compared to physician $(49 \%)$ and in-hospital support (37\%) among mothers who fed formula (Figure 1).

The frequency with which different factors were cited to influence the choice to breastfeed varied significantly between Caucasian and non-Caucasian mothers (Figure 2). Of the 332 mothers who breastfed from birth, 230 (69\%) were Caucasian and 81 (24\%) were
non-Caucasian. Although personal choice was the factor cited most frequently among both Caucasian and non-Caucasian mothers, it was more frequent among Caucasian mothers. Among the latter, cost, books, and availability were cited more frequently as influencing the choice to breastfeed; compared to nonCaucasian mothers for whom, after personal choice, physician was the factor most frequently cited to influence the choice to breast- 


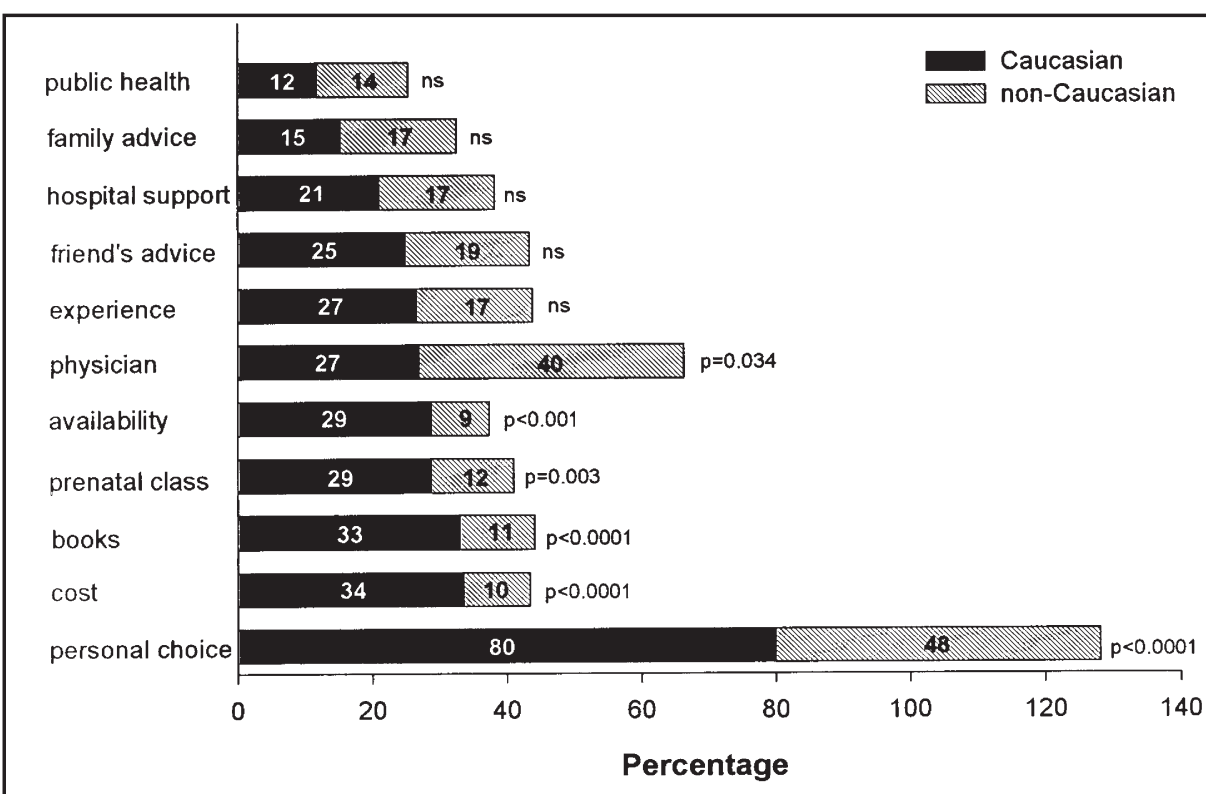

Figure 3. The percentage of breastfeeding mothers who breastfed $<3$ months $(\mathrm{n}=51), 3$ to $<8$ months $(\mathrm{n}=108)$, and $>8$ months $(\mathrm{n}=200)$, respectively, who reported the given factor influenced their choice to breastfeed

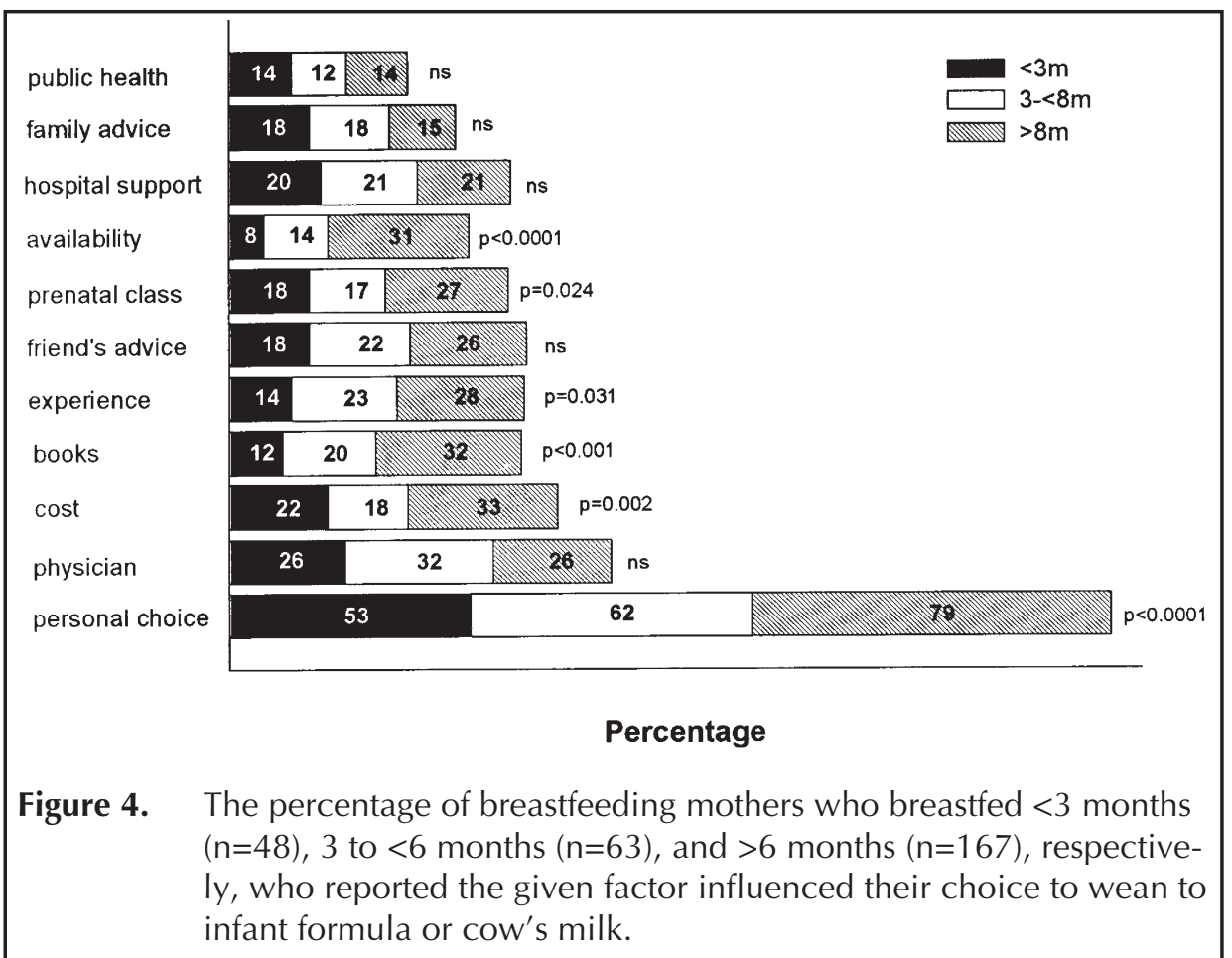

feed, although this was not significantly different from Caucasian mothers.

The frequency with which the different factors were cited as influencing the choice to breastfeed also varied among mothers who breastfed for different durations (Figure 3). Personal choice, books and availability were reported with increasing frequency as duration of breastfeeding increased. For women who breastfed $<8$ months, physician was the most frequently cited factor after personal choice.

Factors influencing mothers' choice to wean to an infant formula or cow's milk

The factors cited most frequently as influencing the choice to wean to an infant for- mula or cow's milk were: returning to work and concern for baby's nutrition (Figure 4). The frequency with which several factors were cited as influencing the choice to wean to infant formula or cow's milk also varied among mothers who breastfed for different durations. Among mothers who breastfed $<3$ months, concern for baby's nutrition and uncomfortable with breastfeeding were the main factors, cited by $58 \%$ and $23 \%$ of mothers, respectively. In contrast, returning to work, concern about milk supply and concern for baby's nutrition, were the most important factors, and cited as important by $29-35 \%$ of mothers who breastfed $\geq 3$ to $<6$ months. Returning to work and personal choice, on the other hand, were most frequently cited factors for those who breastfed $\geq 6$ months. Concern for baby's nutrition and uncomfortable with breastfeeding were reported with decreasing frequency as the duration of breastfeeding increased.

The factor cited most frequently to influence the choice to wean was returning to work, cited by $42 \%$ and $23 \%$ of Caucasian and non-Caucasian mothers, respectively (Figure 5). Of note, the factor cited most frequently by non-Caucasian mothers was concern for baby's nutrition, cited by $38 \%$ and $7 \%$ of non-Caucasian and Caucasian mothers, respectively. However, concern about milk supply was cited as a factor influencing weaning by $28 \%$ of Caucasian mothers, and only $4 \%$ of non-Caucasian mothers.

\section{DISCUSSION}

Infant feeding practices are influenced by a multitude of factors that, according to Social Cognitive Theory, ${ }^{24}$ can be broadly classified into two categories: internal personal and socio-environmental. Figure 6 provides a framework for understanding how infant feeding choices are reciprocally determined by internal personal and socioenvironmental factors. Internal personal factors which influence the decision to breast- or formula-feed may include; cognitive/affective (e.g., knowledge, attitudes, beliefs), outcome expectations (e.g., best for baby), self-efficacy (e.g., confidence, previous experience), biological (e.g., age), or psychosocial (e.g., comfort with breastfeeding in public). ${ }^{25}$ Socio-environmental factors such as institutional (e.g., health 
care practices, policy), social (e.g., family support/dynamics), socio-demographic (e.g., education, income, ethnicity), physical (e.g., fatigue, nipple pain) and others (e.g., cost, availability) may also play important roles in infant feeding choices.

Factors influencing the choice to breastfeed or formula-feed

This study found significant differences in factors reported by mothers to have influenced their decision to breastfeed or formula-feed. Similar to findings of the National Population Health Survey (NPHS), ${ }^{8}$ internal personal, i.e., personal choice, was the primary factor for the decision to breastfeed. In contrast to findings of the NPHS, ${ }^{8}$ but consistent with Bloom et al., ${ }^{17}$ mothers in the current study attributed their decision to formula-feed primarily to health care, i.e., physician and in-hospital support. Consistent with other studies, ${ }^{26-30}$ but in contrast to Reif et al., ${ }^{31}$ this study suggests that positive reinforcement from physicians and other health care practitioners may have a significant impact on the choice to breastfeed, or to use a breastmilk substitute. Of importance also, health care practices that promote infant formula have been found to have a stronger impact on mothers' infant feeding practices than hospital breastfeeding support programs and counselling. ${ }^{32}$

Similar to findings of the NPHS, ${ }^{8}$ socioenvironmental factors such as family advice, friends'/other mothers' advice and prenatal class were reported more frequently by mothers who breastfed than by mothers who fed formula. The selfreporting format used may have been limited by social-desirability bias, resulting in the decision to use formula being attributed to external sources rather than to personal choice. Similarly, it is possible that socio-environmental factors facilitated the expression of the personal choice factor as important among mothers who breastfed.

\section{Factors influencing duration of breast- feeding}

Personal choice was cited with increasing frequency as the duration of breastfeeding increased, i.e., by $53 \%$ of mothers who breastfed $<3$ months, $62 \%$ of those who breastfed $\geq 3$ to $<8$ months, and $79 \%$ of mothers who breastfed $\geq 8$ months. Again, personal choice

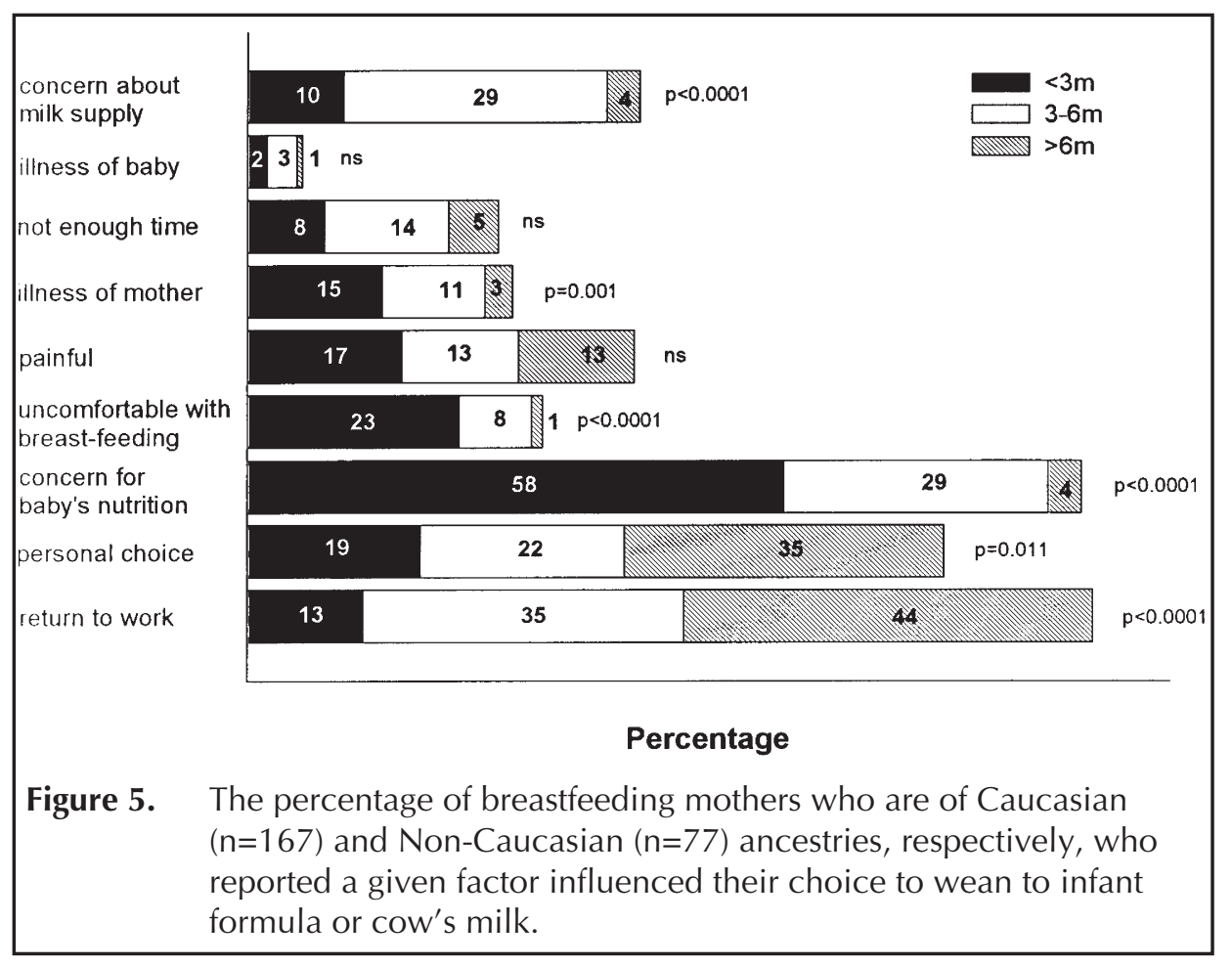

represents a combination of underlying internal personal and socio-environmental factors. In this regard, important predisposing, enabling and reinforcing factors ${ }^{33}$ in the mother's environment can influence internal personal factors such as self-efficacy, attitudes, beliefs, knowledge and skills. The internal personal factors, represented by personal choice, may be shaped by many factors such as a shift in socio-environmental conditions which facilitate, enable, and increase acceptance of breastfeeding. Thus, more aggressive breastfeeding promotion, ${ }^{10,13,34-39}$ and supportive environments ${ }^{40-44}$ are likely to have enabled more mothers to make the personal choice to breastfeed. It is disconcerting that breastfeeding was substantially lower among those women in this study ${ }^{5}$ who are non-Caucasian, have lower income or education, or who are single. Possibly, economic and socio-environmental factors may pose barriers to breastfeeding for these groups of mothers. Indeed, lack of social support ${ }^{15,19,45}$ and financial resources ${ }^{14,26}$ have been shown to be important predisposing factors in the decision to use formula.

\section{Factors influencing choice to wean to infant formula or cow's milk}

As reported by others, ${ }^{26,46}$ a combination of internal personal and socio-environmental factors influence the choice to wean to infant formula or cow's milk. Also, consistent with other reports, ${ }^{8,46}$ internal personal factors, categorized in this study as concern for baby's nutrition and uncomfortable with breastfeeding, were the most frequently cited factors influencing the choice to wean among mothers who breastfed $<3$ months. As suggested by MacLean, ${ }^{8}$ the decision to wean may be too complex to be captured by a simple listing of reasons. Thus, any single response factor, e.g., concern for baby's nutrition, may simply be a proxy for a complex set of interactions which may be interpreted differently by different mothers, or at different stages of breastfeeding.

Previous studies have reported ${ }^{8,14,26}$ medical problems as a primary reason for weaning in the first 3-4 months. Factors such as painful breastfeeding, and illness of mother were reported as factors influencing weaning in the first 3 months by a relatively high number of mothers (about 15\% for each factor). Previous studies have also shown that breastfeeding often is discontinued early due to insufficient milk in the first few weeks. ${ }^{8,15,17,26}$ The current study found that concern about milk supply was more frequently cited among mothers who weaned at $\geq 3$ to $<6$ months, rather than $<3$ or $\geq 6$ months. It is possible that concern about milk supply at $\geq 3$ to $<6$ months may 


\section{Behavioral Factors}

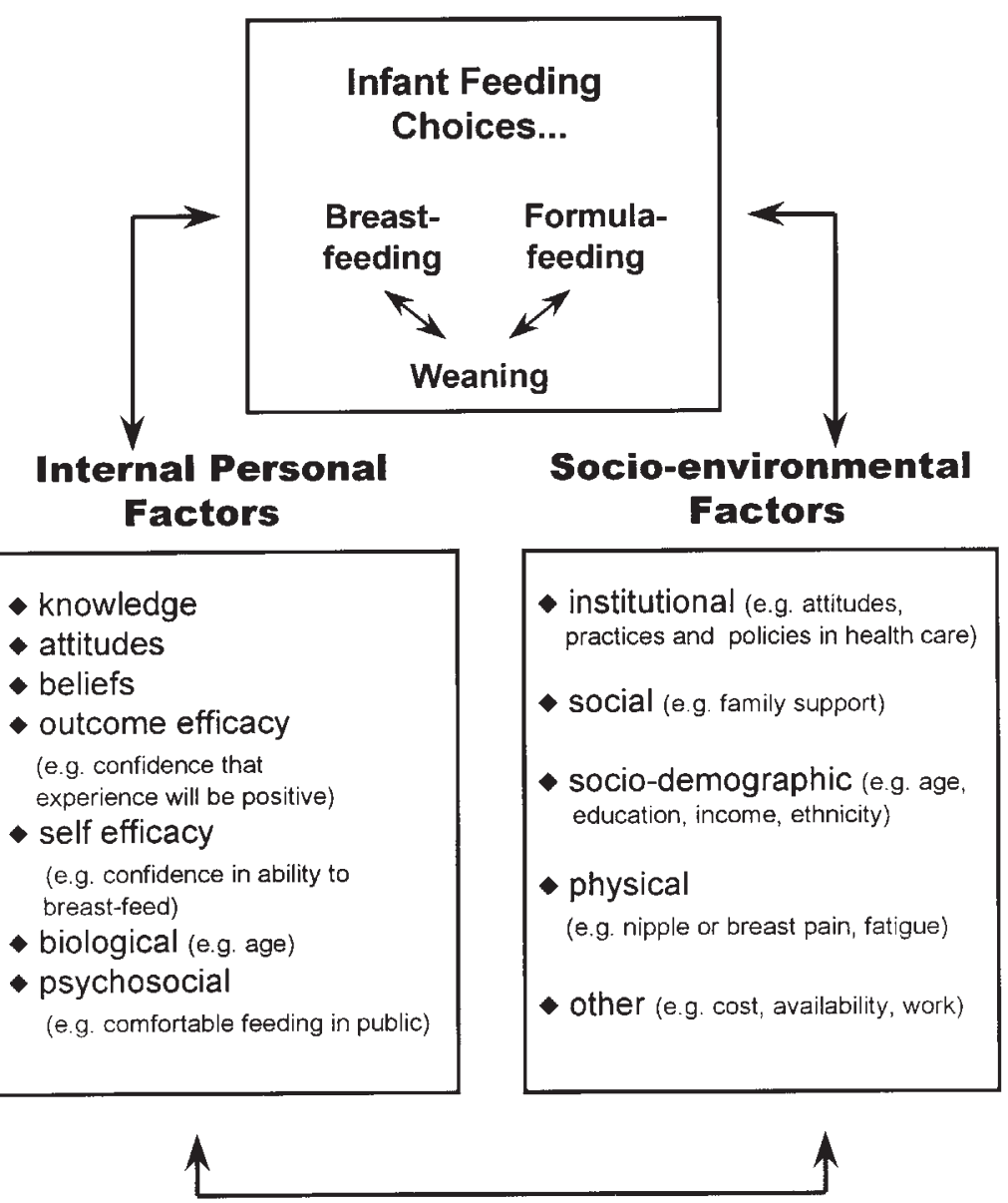

Figure 6. A conceptual framework for understanding factors that influence mother's infant feeding choices. Adapted from Bandura (1986) ${ }^{24}$

reflect mothers' perceptions of infant hunger cues and the need to introduce solid foods, discontinuation of night feedings, and/or some day-time feeds due to return to work. In this regard, Schwartz and Evers $^{47}$ recently reported that the introduction of solids among breastfed infants is primarily related to mothers' perception that their infant is hungry. However, it is important to note in this study that returning to work was the most frequently cited factor in the choice to wean by mothers who breastfed longer than 3 months.

\section{CONCLUSION}

Consistent with Social Cognitive Theory, ${ }^{24}$ the results of this study suggest that both internal personal and socio-environmental factors can influence infant feeding choices.
The relative importance of each, however, seems to be different between mothers who breastfeed and those who formula feed. Primarily, the decision to breastfeed was attributed to personal choice, whereas the decision to formula feed was attributed to advice from health professionals.

It should be noted that the present study involved mothers who had higher levels of education and income, with little participation of single or young mothers. Because of this, factors which influenced the early discontinuation of breastfeeding by the mothers in this study may not be representative of other socio-demographic groups. Participation of younger, less educated women in future studies might be facilitated by using recruitment methods that do not require parents to have their own address and telephone to enable contact, or by working with community groups. An important, but inherent problem in survey methodology is the potential variability in the respondent's interpretation of the question. It is not known if, or to what extent, the mothers in this study may have interpreted questions differently.

The results of the present study also indicate that reasons for discontinuing breastfeeding differ with the time after birth. This suggests that future breastfeeding initiatives could be divided to address three broad areas: 1) prenatal intentions, 2) early postpartum concerns, and 3) later issues surrounding returning to work and infant nutrition. Thus, further studies could be directed to the promotion, protection and support of breastfeeding mothers, specifically addressing barriers to initiation, concerns over early milk supply and infant nutrition, and later issues surrounding the demands of infant feeding and family and work commitments.

Studies consistently show that infant feeding decisions are made early in or even before pregnancy. ${ }^{15,18-21,46,48-53}$ Further, prenatal intentions are the strongest predictor of actual practices. ${ }^{20,48,54}$ Thus, the education and support that physicians and health professionals provide can both help mothers make the choice to breastfeed, and as this study suggests, support their breastfeeding successfully. Strategies that encourage mothers to breastfeed longer are equally important. Unfortunately, a recent study in Vancouver ${ }^{55}$ suggested that current medical training, and physician self-efficacy with regards to breastfeeding support is inadequate.

The present study clearly suggests that factors influencing the choice to wean differ between the early and later postpartum periods. This suggests training of health care professionals and breastfeeding support programs should be tailored to these important concerns. For example, increasing knowledge, skills and exposure to mothers who breastfeed successfully is important for new mothers and can facilitate breastfeeding self-efficacy. Likewise, providing workplace environments sensitive to and supportive of breastfeeding mothers, as well as providing information on how to expand the infant milk diet to include solid foods while enabling breastfeeding to con- 
tinue is important later on. Consideration of these findings by health practitioners, employers and policy makers may be useful in facilitating further advances in breastfeeding promotion strategies and more specific targeting of resources.

\section{ACKNOWLEDGEMENTS}

This study was funded by the British Columbia Medical Services Foundation and completed with assistance from the Vancouver Health Board. We thank Dorcas Lwanga, Carolanne Nelson and Dianne Jacobson for their work on this project; and Vancouver Public Health Nutritionists, Vicki Boere, Barbara Crocker, Corinne Eisler and Helen Yeung for their help in developing the questionnaires, organizing and conducting the nutrition clinics.

\section{REFERENCES}

1. Tanaka PA, Yeung DL, Anderson GH. Infant feeding practices: 1984-85 versus 1977-78. Can Med Assoc J 1987; 136:940-44.

2. Health and Welfare Canada. Report on Present Patterns and Trends in Infant Feeding in Canada. Ottawa: Health \& Welfare Canada, 1991.

3. McNally E, Hendricks S, Horowitz I. A look at breast-feeding trends in Canada (1963-1982). Can J Public Health 1985;76(2):101-7.

4. Myers AW. A retrospective look at infant feeding practices in Canada: 1965-1978. J Can Diet Assoc 1979;40(3):200-10.

5. Williams PL, Innis SM, Vogel AMP. Breastfeeding and weaning practices in Vancouver. Can J Public Health 1996;87(4):231-36.

6. Health and Welfare Canada. Canada's Health Promotion Survey 1990: Technical Report. Ottawa: Minister of National Health and Welfare, 1993.

7. Health and Welfare Canada. Breast-feeding support. Ottawa: Minister of National Health and Welfare, 1993.

8. MacLean HM. Breast-feeding in Canada: A demographic and experiential perspective. J Can Diet Assoc 1998; 59(1):15-23.

9. Canadian Paediatric Society, Nutrition Committee. Meeting the iron needs of infants and young children: An update. Can Med Assoc J 1991;144(11):1451-54.

10. Canadian Pediatric Society, Nutrition Committee. Breast-feeding - Fifteen years of progress. Can J Public Health 1994;1:156-59.

11. Canadian Dietetic Association. Promoting Breast feeding: A role for the Dietitian/Nutritionist. Official Position of the Canadian Dietetic Association; 1989;50:211-14.

12. Breastfeeding Committee of Canada. Breastfeeding statement of the Breastfeeding Committee of Canada. J Can Diet Assoc 1998;59(1):11-13.

13. WHO/UNICEF. Innocenti Declaration on the Protection, Promotion and Support of Breastfeeding. Breastfeeding in the 1990's:
Global Initiative WHO/UNICEF sponsored meeting, Florence, Italy, 1991.

14. Ryan AS, Pratt WF, Wysong JL, et al. A comparison of breast-feeding data from the National surveys of family growth and the Ross Laboratories Mothers' Survey. Am J Public Health 1991;81(8):1049-52

15. Sacks SH, Brada M, Hill AM, et al. To breast feed or not to breast feed. Practitioner 1976;216:183-91.

16. Ever-Hodani P, Seidman DS, Manor O, Harlop S. Breast feeding in Israel: Maternal factors associated with choice and duration. J Epidemiol Commun Health 1994;48:281-85.

17. Bloom K, Goldbloom RB, Robinson SC, Stevens FE. Factors affecting the continuance of breastfeeding. Acta Paediatr Scan (Supp.) 1982;300:9-14.

18. LeFevre M, Kruse J, Zweig S. Selection of infant feeding method: A population-based study in a rural area. J Fam Pract 1987;24:487-91.

19. Rousseau EH, Lescop JN, Fontaine $S$, et al. Influence of cultural and environmental factors on breast-feeding. CMAJ 1982;127:701-4.

20. Entwisle DR, Doering SG, Reilly TW. Sociopsychological determinants of women's breast-feeding behaviour: A replication and extension. Am J Orthopsychiatry 1982;52:244-60.

21. Losch M, Dungy C, Russell D, Dusdieker LB. Impact of attitudes on maternal decision regarding infant feeding. J Pediatr 1995;126:507-14.

22. Kearney MH. Identifying psychosocial obstacles to breast-feeding success. JOGNN 1988; March/April: 98-105.

23. Innis SM, Nelson CM, Wadsworth LD, et al. Incidence of iron-deficiency anaemia and depleted iron stores among nine-month-old infants in Vancouver, Canada. Can J Public Health 1997:88(2):80-84.

24. Bandura A. Social Foundations of Thought and Action: A Social Cognitive Theory. Englewood Cliffs, NJ: Prentice Hall, 1986.

25. Neumark-Sztauber D, Story M. The use of health behaviour theory in nutrition counselling. Top Clin Nutr 1996;11:60-73.

26. Bloom K, Goldbloom RB, Stevens FE. Breast vs. formula feeding: I. Factors affecting the mother's choice of infant feeding method. Acta Paed Scand Suppl 1982;300:3.

27. Haider SA. Encouragement of breast-feeding. (Letter) BMJ 1976;1:650.

28. Wright W, Walker P. Prediction of duration of breast-feeding in primiparas. J Epidemiol Commun Health 1983;37:89-94.

29. Lawrence RA. Practices and attitudes toward breast-feeding among medical professionals. Pediatrics 1982;70:912-20.

30. Bernard-Bonnin AC, Stachenko S, Girard G, Rousseau E. Hospital practices and breast-feeding duration: A meta-analysis of controlled trials. Birth 1989;16:64-66.

31. Reif MI, Essock-Vitale SM. Hospital influences on early infant-feeding practices. Pediatrics 1985;76:872-79.

32. Labbok MH, Simon SR. A community study of a decade of in-hospital breast-feeding: Implications for breast-feeding promotions. Am J Prev Med 1988;42(2):62-67.

33. Green LW, Kreuter MW. Health Promotion Planning: An Educational and Environmental Approach 2nd Ed. Mountain View, CA: Mayfield, 1991.

34. World Health Organization. International code of marketing of breast milk substitutes. 1981; Resolution WHO, 34:22.

35. Nutrition Committee of the Canadian Paediatric Society and the Committee on Nutrition for the American Academy of Paediatrics. Breast-feeding: A commentary in celebration of the International Year of the Child, 1979. Pediatrics 1978;62:591-601.

36. Myers AW. National initiatives to promote breast-feeding: Canada, 1979-85. In: Jelliffe DB, Jelliffe EFP (Eds.), Programs to Promote Breastfeeding. Oxford: Oxford University Press, 1988.

37. Nutrition Committee, Canadian Pediatric Society. Breast-feeding: What is left besides the poetry? Can J Public Health 1978;69:13-20.

38. Freil JK, Hudson NI, Banoub S, Ross A. The effect of a promotion campaign on attitudes of adolescent females toward breast-feeding. Can J Public Health 1989;80:195-99.

39. Myers AW. The national breast-feeding promotion program. 2. Public information phase - a note on its development, distribution and impact. Can J Public Health 1983;74:404-8.

40. Katcher AL, Lonese MG. Breast-feeding by employed mothers: A reasonable accommodation in the workplace. Pediatrics 1985;73:644-47.

41. Barber-Madden R, Petschek MA, Parker J. Breast-feeding and the working mother: Barriers and intervention strategies. J Public Health Pol 1987; Winter:531-41.

42. Jones D, West R. Effect of a lactation nurse on the success of breast-feeding: A randomised controlled trial. J Epidemiol Commun Health 1986;40:45-49.

43. Lynch S, Koch A, Hislop T, Coldman A. Evaluating the effect of a breast-feeding consultant on the duration of breast-feeding. Can J Public Health 1986;77(3):190-95.

44. Morse JM, Bottorff J, Boman J. Patterns of breast-feeding and work: The Canadian experience. Can J Public Health 1989;80:182-88.

45. Freed GL, Jones TM, Schandler RJ. Prenatal determination of demographic and attitudinal factors regarding feeding practice in an indigent population. Am J Perinatal 1992;9:420-24.

46. Eastham E, Smith D, Poole D, Neligan G Further decline of breast-feeding. BMJ 1976;1:305-7.

47. Schwartz C, Evers S. Infant feeding practices in low-income communities in Ontario. J Can Diet Assoc 1998;59(1):30-34

48. Aberman S, Kirchoff KT. Infant-feeding practices, mothers' decision making. J Obstet Gynecol Neonatal Nurs 1985;14:394-98.

49. Jones RAD, Belsey EM. Breast-feeding in an inner London borough: A study of cultural factors. Soc Sci Med 1977;11:175-79.

50. Mackey S, Fried PA. Infant breast and bottlefeeding practices: Some related factors and attitudes. Can J Public Health 1981;72:312-18.

51. Sarett HP, Bain KR, O'Leary JC. Decision on breast-feeding or formula feeding and trends in infant-feeding practices. Am J Dis Child 1983;137:719-25.

52. Sjolin S, Hofvander Y, Hillervik C. A prospective study of individual courses of breast-feeding. Acta Paediatr Scand 1979;68:521-29.

53. Beske EJ, Garvis M. Important factors in breastfeeding success. Am J Maternal Child Nursing 1982;7:174-79

54. Coreil J, Murphy JE. Maternal commitment, lactation practices and breast-feeding duration. J Obstet Gynecol Neonatal Nurs 1988;17:237-78.

55. Burglehaus MJ, Smith LA, Sheps SB, Green LW. Physicans and breastfeeding: Beliefs, knowledge, self-efficacy and counselling practices. Can J Public Health 1997;88(6):383-87.

Received: September 24, 1997

Accepted: October 22, 1998 